of age, gave a circumference at one metre from the ground of I.52 metres, another of eleven years growth gave $I^{\prime} 42$, and another, planted in fresh alluvial soil, nine years of age, gave I.57 metres-about six inches more, Col. Playfair says, than he could embrace with both arms. To the question of the sanitary effects of Eucalyptus a good deal of attention has been directed. An inquiry was instituted by the Society of Physical and Natural Sciences at Algiers under the presidency of Dr. Bertherand, and the result was that from thirty localities reports were received, all of which speak favourably of the Eucalyptus as a fever 'preventive. On the banks of Lake Fetzara, near Bône, 60,000 young trees of Eucalypius giobulzıs were planted in 1869 . At the present time they have attained a height of from 7 to 8 metres each, and have, it is said produced a very marked effect on the locality. Such was the feverish condition of this district on the annual fall of the water and the denudation of its banks that the director of the Jardin d'Essai, who went to examine the condition of the plants, was immediately seized with a violent fever which lasted twenty days. This gentleman, however, now reports that the miasmatic influences which affected him so strongly then have disappeared, and the mosquitoes which rendered the place uninhabitable have disappeared with them. At the great iron mines of Mokta et Hadid it was formerly impossible for the workmen to remain there during the summer; those who attempted to do so died, and the Company was obliged to take the labourers to the mines by train every morn. ing, and to carry them back to Bône at night, a distance of 33 kilometres each way. From I 868 to 1870 the Company planted more than 100,000 Eucalyptus trees, and now the workmen are able to live all the year through on the scene of their labour. Consul Playfair advances the following reasons as accounting for the causes of the improvement in climate from planting Eucalyptus trees:"In some places," he says," the trees destroyed miasma by utilising the moisture of the soil in which they were planted, and thus draining marshes; the emanations from their leaves also may have produced a salutary effect. They contain a large quantity of essential oil very similar to turpentine, which they emit in great quantities, especially when stirred by the wind, and this acts, it is supposed, as a febrifuge." We are further told that considerable numbers of Eucalyptus have been planted all along the cailway from Algiers to Oran. Where this line passes through the Metidja the trees have grown most successfully, but in the Chelif they have proved almost an entire failure. This, however, may have been due to their receiving no attention whatever after being planted.

WE have received reprints of two papers by Dr. C. Le Neve Foster, one "On Some 'Tin-Lodes in the St. Agnes District," and the other "On a Deposit of 'Tin at Park of Mines."

WE have received an interesting little publication, by $\mathbf{M r}$. Edwin Lees, F.L.S., reprinted from the Transactions of the Malvern Naturalists' Field Club, on "The Forest and Chase of Malvern, its Ancient and Present State," with notices and illustrations of the most remarkable old trees remaining within its confines.

THE additions to the Zoological Society's Gardens during the past week include a Bonnet Monkey (Macacus radiatus) from India, presented by Mr. Richard Turner; an"Azara's Fox (Canis azarc), two Brazilian Cariamas (Cariama cristata), a crested Screamer (Chauna chavaria) from the Argentine Republic, two Crab-eating Raccoons (Procyon cancrivorus) from South Brazil, a Yarrell's Curassow (Crax carunculata), a Sclater's Curassow (Crax sclateri), a Globulose Curassow (Crax globulosa), a Garden's Night Heron (Nycticorax gardeni) from Brazil, four Silky Cow Birds (Motothrus bonariensis), a Banded Cotinga (Cotinga cincta), a Yellow-footed Thrush (Turdus flavipes) from Bahia, deposited; an Ostrich (Struthio camelus) from Africa, recelved in exchange.

\section{THE LIMITS OF NATURAL KNOWLEDGE}

II.

HAVING considered the capacity of the subject and the accessibility of the object, we must now turn our attention to the copula, i.e., the demands which we make of knowledge.

As all conceptions which we form of nature are exclusively the results of sensual perception, our knowledge cannot go further than to compare the phenomena we have observed, and judge them with reference to one another. If any phenomenon of a special nature occurred only once, if, for instance, we were the only existing organisms our insight would be extremely limited, because all our knowledge of the human organism we have essentially obtained from its connection with all other organic beings. The comparison of many phenomena gives us a unit or a stanclard by which we can measure and determine each single one. We therefore obtain just as many measures as there are properties in nature which we can perceive by our senses or which can be inferred from sensual perceptions by our judgment. As these measures are deduced from finite facts they have only a relative value, and our knowledge remains finite for the same reason.

We therefore understand a phenomenon, we know its value with regard to other phenomena if we can measure, count, or weigh it. We have a clear idea of the size of the lowest fungus, of which we must place some $2,000,000$ or $3,000,000$ individuals side by side to complete the length of a metre, of the size of an elephant, of the earth, of our solar system, the radius of which is somewhere about $3,000,000,000$ miles. We have a clear idea of the time in which a ray of light carries to our eye the writing of a book which we read, and which is about the $300 \frac{1}{00000 \text { th part }}$ of a second-of the life-time of the lowest fungus which in a plant-box or in the human body is replaced by a new generation after only twenty minutes-of the life-time of an vak which may be several thousand years, and of the 500,000,000 years which have passed since the generation of crganisms upon our earth.

Natural bodies are composed of parts; the value of their internal structure, of their organisation, is exactly determined by the quantity, nature, and arrangement of these parts. They therefore give us the measure by which we judge the compound whole, and with which we measure its organisation as it were. The morphological or descriptive natural sciences by these measurements obtain their scientific data. Chemistry, which at the present time is still an eminently morphological science and which investigates the formation of compounds from elementary atoms, and mineralogy, which presupposes the uniform arrangement of molecules, have arrived at a state of great perfection. The common measure for organisms is the cell, and further on the organ; the common measure for the systematic unities of organic nature (for varieties, species, genera) we find in individuals and generations.

We are enabled not only to compare the different objects and measure them by one another, but in as far as it changes, we may also compare a system, a unit (einheitliche) group of things of similar nature, with itself and measure it by itself. The knowledge of the change is complete if the later stage is proved to be the necessary consequence of the earlier one, or the latter to be the necessary predecessor of the later one, if one can be constructed from the other, if therefore both stages can be brought into the relation of cause and effect to one another.

In the elementary domains of the material this causal relation is the mechanical necessity, which for two successive stages demands the equal sum of motion in a certain direction (or living force) and of potential energy. Among the sciences which apply here astronomy ranks first ; next in efficiency are several physical sciences, particularly the mechanical theories of heat and optics. Physiology, or the physics of the organic world, tries to penetrate into a far more difficult and more complicated domain, by following the footmarks of her older sister.

In the higher domains of the material we cannot for our causal knowledge uphold the demand for this mechanical necessity. Indeed this is perhaps impossible in the case of all structure.

I Address delivered at the Munich meeting of the German Associa tion, by Prof. C. von Nägeli, of Munich. (The atthor, in a note to the German original, remarks that this lecture had to replace another in the programme, which had been promised by Prof. Tschermak, of Vienna. A the eleventh hour Prof. Tschermak announced his inability to atzend the Munich meeting, and the author was requested by the secretaries to fill the gap thus occasioned. The address therefore, the author states, bears the stamp of its hasty origin, as it was written during a journey in the Alps when there was neither sufficient leisure nor opportunity for careful and elaborate work.) Continued from p. 535 . 
We shall probably never succeed in explaining definitely why the origin of a chemical compound and of a crystal must be the necessary result of known forces and motions of elementary atoms and molecules. This will be the case still less with the formation of cells, with the growth of organisms, with the propagation and inheritance of peculiarities. And yet we may, even in these domains, speak of causal knowledge with some show of right, only the elements which constitute this knowledge are not simple forces and motions, but very complicated combinations of these, which are not analysed further. Our causal knowledge will arrive at perfection when we succeed in predicting future events with the same certainty and exactness as astronomers do. Now we already find certain indications of this in the chemistry of compounds and in organic morphology, since it is possible to make deductions from certain stages of development of an organism with regard to earlier or later stages of the same. And a time will arrive when the organic laws of the still youthful history of development of the individual and of the still younger history of development of the species will have been more investigated, and when we need no longer presuppose ontogenetic and phylogenetic necessity as a matter of course, but when we will also be able to understand the cause of this necessity.

The objection will perhaps be raised that causal knowledge certainly consists of our understanding the necessity, as in the case of mechanics, but that this does not apply in domains where we must start from uninvestigated compound objects. The mechanics of the heavens is based upon general gravitation and centrifugal force, and both are simple forces acting in a stright Iine. But both are hypotheses, which rest upon our experience and of the reason of which we are ignorant. Astronomy reveals to us the necessity of astronomical phenomena only under the supposition of facts we have experienced-not the necessity in itself. If we were to demand that to our knowledge the "why?" should be clear, there would not even be any astronomical nor yet any physical knowledge. In the organic domains causal knowledge is entitled to the same imporiance as physical knowledge is in the inorganic field. By experience we know a system of forces and motions, for example, the cell. We ascertain certain general facts relating to this system (in the same way as with gravitation and centrifugal force in the heavens), and we use these facts for further deductions. Our insight into the necessity of some process of growth consists in our recognising this process as a necessary consequence of those facts.

Our knowledge of natural things therefore rests upon our being able to measure them, either by themselves or by one another. Another method of observation leads us to the same result. We maderstand and master something perfectly, if we create it our. selves, because in this case we see its cause. The only thing in the domain of knowledge, which, based upon our sensual per. ceptions, we can accomplish, is mathematics. The tenor of this formal science is perfectly clear to us, because, indeed, it is the product of our own mind. We can therefore also understand real things with certainty, as far as we find mathematical ideas, number, magnitude, and evergthing which mathematics deduces from these, realised in them. Natural knowledge therefore consists in our applying mathematical methods to natural pheno. mena ; to understand a natural event means nothing else as it were, than to repeat it in thought, to reproduce it in our mind.

While designating natural knowledge as mathematical and at the same time as relative, which judges things according to a measure deduced from themselves, I depart considerably from the views of my predecessor, Prof. Du Bois Reymond. He considers it to be a condition of natural knowledge, that we should succeed in reducing the changes in the material world to motions of atoms caused by their central forces which are independent of time, or in other words, in resolving natural phenomena into the mechanics of atoms.

While Du Bois Reymond thus starts from the undeniable fact that a compound can only be known from its parts, yet he stops not at the finite and real parts, but continues the division down to the real unities, which are unthinkable, and thus he marks out the conditions for impossible absolute knowledge. But as we do not crave divine but only human knowledge, we may not ask more of the latter than that in each finite sphere it should advance as far as mathematical unclerstanding ; and the saying of Kant, that in each special natural science we can find only as much real science as we can find mathematics in it, is after all still quite correct.

If $\mathrm{Du}$ Bois Reymond wishes to continue the analysis of matter down to atoms with simple central forces, he carries a favourite method of modern physics and physiology to extremes, and if he shows that this way of proceeding does not lead to understanding, he destroys the claims of exclusive adherence to the domain of science, which the employers of this method sometimes raise If physics and physical physiology go back to supposed atoms, material points, elements of volume which we imagine to be infinitely small, then this hypothesis is justified inasmuch as the real chemical molecules are so small that we may, without error of calculation, consider space to be continuously filled with matter: For instance, for a molecule of albumen, consisting of numerous atoms of carbon, hydrogen, oxygen, and nitrogen, we may substitute a mass differential of this compound. At all events it is useful to make this hypothesis, as it must be seen how far a conception of this kind can be treated mathematically, and as from the result we may draw conclusions backwards with regard to the composition of matter.

But we must beware of the opinion which is frequently associated with this method, that it alone is natural science and that knowledge can only be gained by employing it. In this case we would have to confine our desire to unrerstand nature to a single domain, and ye would lose others which are capable of safe confirmation. Natural knowledge need not necessarily begin with hypothetical and the smallest unknown things. It begins wherever matter has shaped itself to unities of the same order, which may be compared to and measured by one another, and wherever such unities combine to form compound unitiss of a higher order, and yield a measure for their comparison with one another. Natural knowledge may begin at every age from the organisation or composition of matter; at the atom of chemical elements, which forms the chemical compounds; at the molecule of the compounds, which composes the crystal; at the crystalline granule, which composes the cell and its parts; at the cell, which builds up the organism; at the organism or individual, which becomes the element of the formation of species. Each natural scientific discipline has its justification essentially in itself.

Our knowledge of nature is therefore always a mathematical one, and consists either in simple measurement, as in the mor. phological and descriptive natural sciences, or in causal measure. ment, as in the physical and physiological sciences. By means of mathematics, however, by weight, raeasure, or number, we can only understand relative or quantitative differences. Actua qualities, absolutely differext properties, escape our understanding, since we possess no measure for them. We cannot conceive really qualitative differences, because qualities cannot be com. pared. This is an important fact for our attempts to understand nature. Its consequences are, that if within nature there are domains which are qualitively or absolutely different, scientific knowledge is cnly possible separately within each single one of them, and that no connecting bridge leads from one domain into another. But another consequence is that, as far as we can investigate nature continuously, as far as our measuring knowledge advances without gaps, and especially as far as we understand one phenomenon through another, or can prove it to have arisen from the other, that absolute differ. ences, chasms which cannot be filled, do not exist at all in nature.

I have tried to determine the capacity of the Ego, the accessibility of nature, and the essence of human understanding. It is easy now to fix the limits of natural knowledge.

We can know only what our senses acquaint us with, ancl this is limited in time and space to an infinitesimal domain, and perhaps only to a part of the natural phenomena occurring in this domain, on account of a deficient development of our organs of sense. Of that with which we are acquainted at all, we can only know the finite, the changeable and perishable, only what is relative and differs by degrees, because we can only apply mathematical ideas to natural things, and can judge the latter only by the measures we have gained from themselves. Of all that is endless or eternal, of all that is stable or constant, of all absolute differences we have no conception. We have a perfect idea of an hour, a metre, a kilogramme, but we have no idea of time, space, matter and force, motion and rest, cause and effect.

The extent and limit of our possible natural knowledge we may shortly and exactly state thus:- We can only knov the finite, but we can know all the finite which comes within reach of our sensual perception.

If we are clearly conscious of this limitation of our lnnowledge we free natural observation from many difficulties and errors, which consist, on the one hand, in the attempt to investigate not only the really finite, but a mixiure of the finite and the eternal, which is uninvestigable; and, on the other hand, in our not 
following the finite strictly and incessantly, but stopping here and there in the midst of it and changing it for the eternal.

It would lead me far indeed, if I were to consider the consequences singly, which have arisen from the want of a correct method based upon principles. The most remarkable ones, which at the same time claim a general interest, are the opinions, that finite nature is divided into two radically different domains, and particu. larly that there is an insuperable limit between inorganic and organic, or between material and spiritual nature. I will speak only of the latter opinion.

The antagonists of an intimate connection between material and immaterial nature draw the line of separation in different places. In the opinion of some, living nature generally (or "lifecndowed" (beseelte) nature, inasnuch as life is also ascr.bed to plants) represents something absolutely special, while others admit this only for the animal world endowed with sensation, and yet others only for the spiritually conscious human race; new immaterial or eternal principles are said to apply to the higher grades. Du Bois Reymond holds the second of these views; he says that in the first trace of pleasure which was felt by one of the simplest beings in the beginning of animal life upon our earth, an insuperable limit was marked, while upwards from this to the most elevated mental activity, and downwards from the vital force of the organic to the simple physical force he nowhere finds another limit.

It is difficult for the naturalist to oppose the supposition of immaterial principles, which are said to arise suddenly here and there in nature, as it places itself at once upon a stand-point which floats in the air outside of natural science, and cannot, therefore, be attacked directly and contradicted by him. Natural science can only show that this supposition is superfluous, because everything can be explained in a natural way, and also improbable, because otherwise a contradiction is introduced into finite nature which gainsays the whole of our experience, and offends our mental desire to find causal relations everywhere.

Experience shows that from the clearest consciousness of the thinker downwards, through the more imperfect consciousness of the child, to the unconsciousness of the embryo, and to the insensibility of the human ovum, or through the more imperfect consciousness of undeveloped human races and of higher animals to the unconsciousness of lower animals, and of sensitive plants, and to the insensibility of all other plants, there exists a continuous gradation withont definable limit, and that the same graclation continues from the life of the animal ovum and the vegretable cell downwards through organised elementary and more or less lifeless forms (parts of the ceil) to crystals and chemical molecules.

But the conclusion we draw by analogy is this:-Just as all organisms consist of and have been formed of matter, which occurs in inorganic nature, so the forces, which are inherent in matter, have of course entered into the formations as well. If matter combines with other matter, then their forces unite to some total result, and this represents the new property of the resulting body; this property is of course only relative. Thus vermilion is mercury + oxygen - heat; sugar is carbon + hydrogen + oxygen - heat. And thus life and feeling are new relative properties which albumen molecules obtain under certain circumstances. Accordingly, experience shows that spiritual life is everywhere connected in the most intimate manner with natural life, that the one influences the cther and cannot exist without the other. It is necessary, therefore, as everywhere in nature forces and motions are united only with material particles, that the spiritual forces and motions also appertain to matter, in other words, that they are composed of the general forces and motions of nature and are connected with them as cause and effect. No naturalist can avoid the conception of a causal connection of this nature, unless he becomes unfaithful, consciously or unconsciously, to his first principle. The problem is, therefore, to understand how the forces of inorganic matter combine in matter which forms into organisms, so that their result represents life, sensation, and consciousness. The solution of this problem is yet very remote; but it is possible. We may give sufficient indications for each single point.

Permit me to speak more minutely of one of these points; mean the one in which my predecessor sees a limit to natural knowledge. This is all the more tempting since for the rest $D u$ Bois Reymond places himself upon the basis of the causal principle, if indeed not in words quite so direct, yet quite as determincd and unconditional; and since if this one gap were filled, no other would exist for his point of view. To him the whole world-history, even the who!e system of the universe, is the consequence of the mechanics of atons. There is no action of the mind, which could not be calculated from the forces and the motions of matter, if it were possible to know these. The material occurrences which are connected with the solution of an arithmetical problem, with the pleasure of musical sensation, with the intellectual pleasure over a scientific discovery, are pro. ducts of cerebral mechanics. The mind can indeed be looked upon as the secretion of the substance of the brain, in the same way as gall is the secretion of the liver, as Karl Vogt, and previously Cabanis, have said.

Du Bois Reymond declares all this to be inteligible in principle; but, he says, we learn to know only the conditions of mental life, but not how from these conditions mental life results. Sensation and conscionsness doubtless accompany the material processes in the brain by necessity, but they stand outside of the causal law and remain eternal enigmas to us.

It is not uninteresting to follow Du Bois Reymond's view, which I have just stated and which he details and illustrates with various examples, into its consequences, and to consider clearly its general result. We then arrive at this:-The finite mind, as it has developed itself through the animal world up to man, is a double one; on the one side the acting, inventing, unconscious, naterial mind, which puts the muscles into motion and determines the world's history; this is nothing eise but the mechanics of atoms, and is subject to the causal law; and on the other side the inactive, conternplative, remembering, fancying, conscious, immaterial mind, which feels pleasure and pain, love and hate; this one lies outside of the mechanics of matter and cares nothing for cause and effect.

Generaily both sides of mental life are collectively called nind. Du Bois Reymond exclusively designares the later as mind, and if the separation existed in the way desc ibed this would cerrainly be the truly unintelligible secretion of the material mind, or of the atoms of the brain ; it woul I not be anything but the useless ornament of this material mind, its infallibly tollowing, unreal shadow. Because it stands outside of the chain of cause and effect, it is powerless and without influence upon actions; without it the world's history would have run exactly the same course as it did. Also without consciousness mathematical formulas would have been invented, written down, taught, and applied, telegraphs and steam engines would have been constructed; also without consciousness theological and philosopinical discussions would have been held, printed, read, and their authors burnt at the stake; also without conscious memory lessons would have been learnt by heart in the schools and examinations held; also without musical sentiment music would have been composed, repeated at rehearsals, performed and listened to with all external signs of pleasure or disapprobation; also without poetical or artistic sentiment poets, painters, and sculptors would have produced their works, and these would have been admired and criticised. Therefore without a conscious and perceived mental life, we should have thought, done, and spoken everything, but only mechanically, and not otherwise than a very artistically. invented dead automaton would think, act, and speak.

We cannot deny the sublimity of this conception of the universe; the impression it makes upon the naturalist must be all the greater, because it proceeds consequentially every where and does not offend any natural scientific principle; as to the immaterial and the unintelligible it assigns a domain, which lies outside of the comnection of natural and real things. For this reason also this conception cannot be discussed from a natural scientific point of view. And yet to the naturalist certain objections present themselves.

Can we imagine that so many occurrences, which most evidently resulted from sensation and consciousness, have some other sensationless and unconscious origin? Can we imagine that sensation and consciousness are so entirely useless, and while everywhere utilicy (zweckmässigkeit) is so eminently promınent in organic nature, that so useless and superfluous a phenomenon should occur just where we expect the greatest utility? Can we imagine that the causal principle, which governs the whole of nature, fails us just at the most important part? Can we imagine that organised matter accidentally and without cause acquires a property (sensation and consciousness), and loses it again accidentally and without effect, because, in the ovum and in the embryo the conscious and perceived mental life would not be present, it would arise gradually, it would be lost in sleep every night, obtained again more or less completely in the waking state, and annihilated for ever in death?

The conscience of the naturalist is little satisfied by this new 
dualism, although he cannot directly contradict it. It is true that this dualism is infuitely different from the ordinary dualisn, since it assigns the exclusive power to the forces of nature, anc to the mind only an inactive, empty dignity, and thus hinders in no way the strictly causal or materialistic conception of all material occurrences, also of those which bring about mental life. But nevertheless we would wish for a solution which corresponds more to our experiences and to our theoretical conceptions. And I believe that this solution lies very near if we extend our judgment of the phenomena in organic nature to those of inorganic nature as well.

It is quite correct in $\mathrm{Du}$ Bois Reymond to say that we can only know the material conditions of mental life, but that how this results from those conditions remains a secret to us for ever. But it would be an error to suppose that we generally understand the origin of natural life from its causes. In all purely material phenomena we find the same barrier as in the mental ones. We know by experience that in the inorganic world the cause is lost in the effect, but we cannot understand the nature of the transfer. We know by experience that a stone thrown up into the air falls to the ground, and we say that this happens because the earth attracts it ; but this attraction is for tis incomprehensible.

What we do know is, that two bodies which are apart a:t upon one another in such a way that, if there is no otstacle, they approach one another until they touch. In what, however, this action consists, how it adduces the mutual motion, is for us just as unintelligible, and will remain just as eternal an enigma, as the origin of sensation and conscious. ness from material causes. With all material, physical, and chemical phenomena, we find the same. A body charged with positive electricity, and another one charged with negarive electricity, move towards each other; two bodies similarly electrified revel one another. If we say that in the former case attraction, and in the second repulsion takes place, then these are only short expressions which comprise whole series of similar phenomena, but give no explanations. But we accustom ourselves to such expressions; little by little we use them so frequently and earily, that we believe we really understand the phenomena they designate. And that is why the view is generally held, that nature in her simpler inorganic phenomena offers no difficulties to our conception, whereas in reality the difficulties are every. where the same in principle.

The objection will perhaps be raised, that the two sides of the question are not quite so equal as I say; that with purely material phenomena the relation between two material particles, which causes their motion, is indeed incompreliensible; that with mental phenomena this incomprehensible relation between the material paricles is also given; but that something else, something new is added, namely, the mental action which accompanies the material phenomenon. But this objection, if indeed we raise it, would be unfounded; we should have overlooked that the two sides into which we should divide the mental phenomenor are equally present with the purely material phenorxenon, only that they are not separately conceived here but in one, namely, the sensation and the reartion which this sensation causes.

This fuct, that the simplest inorganic phenomena are quite as inaccessible in their origin as the most complicated occurrences in the human brain, constructs the bridge which may lead us to a monistic (iinheitliche) conception of nature. Let us start from what we know-and in this case it is the complicated mental phenomenon -in order to obtain from it a conception of what we stiil ignoran of.

We know mental life only from our subjective experiences; we know that we draw conclusions, that we remember, that we feel pleasure and pain. That similar but undeveloped pheno. inena , ccur wuh children and higher animals, we conclude from their actions and from their somatic manifestations, which we interuret as the expression of emolion and sensation. Actual proufs that even the lower animals still possess sensation, wihich is only different in degree from the conscious sensation of man, we have only in their movements consequent upon some irritation, and in the important circumstance that these movements upon irritation in the ascending animal classes pass through all gradations upwards to the most complicated phenomena in the human brain. From these irritation-movements of the lowest animals we imperceptibly get to those of the unicellular plants and of the sensitive plants, and thence to the phenomena of the apparently insensible plants, which cannot be distinguished from the phenomena of morganic nature. Between the irritationmovenents of piants and animals, however, and the apparentiy insensible inorganic movements, there is no other difference but this, that in the case of irritation a powerful cause acts upon numberless material particles arranged in a similar manner, and thus produces a movement of place or sensation which becomes perceptible to our senses, while when this perceptible movement is wanting, the cause of the molecularimovements, which talse place in several directions, is not called an irritation.

In the higher animal world sensation is distinctly present in the movements consequent upon irritation. We must therefore credit the lower animals with it as well, and we have no reason to deny it in the case of plants and inorganic bodies. Sensation causes us to feel pleasure or displeasure. Generally speaking the feeling of pleasure arises when our natural inclinations are gratified, and the feeling of pain when this gratification is denied. As all material phenomena are com. posed of the motions of molecules and elementary atoms, pleasure and pain must have their original seat in these particles; they must be caused by the manner in which these infinitesimal particles are able to respond to the attracting or repelling forces which act upon them. Sensation, therefore, is a property of the albumen molecules; and if we rant it in the case of albumen mulecules we must grant it likewise in the case of the molecules of all other substances.

Let us now consider the relation of two molecules of different chemical elements (for instance that of a hydrogen molecule and one of oxygen), which are at a minute distance from each other. Each of them, according to the present notions of chemistry, consists of two not further divisible, but yet decidedly compound atoms. By means of its composition the atom has different properties and forces, and therefore acts differently (attracting or repelling) upon other atoms. The two molecules in question experience or feel their mutual presence in a different manner; they act upon each other with different attractive or repulsive power.

Let us examine what happens in the case of a certain attrac. tion, for instance, in that of a chemical one. Three possibilities exist : either the molecules follow their inclination and approach one another, or they are condemned to rest through other forces which are equal to the attracion, or they move away from one another, the forces counteracting their inclination gaining the upper hand. The same three possiblities are given for a certain repulsion, for instance, through heat ; the two molecules follow their natural inclination and move away from each other, or they remain at the same distance, or they are pushed towards one another by other causes, their inclination being overcome.

Now if the molecules possess anything which is ever so dis. tantly related to sensation, and we cannot doubt it, since each one feels the presence, the certain condition, the peculiar forces of the other, and, accordingly, has the mclination to move and, under circumstances, really begins to move, becomes alive as it were, moreover, since such molecules are the elemen's which cause pleasure and pain; if therefore the molecules feel something which is related to sensation, then this must be pleasure if they can respond to attraction and repulsion, i.c., follow their inclination or disinclination; it must be displeasure if they are forced to execute some opposite movement, and it must be neirher pleasure nor displeasure if they remain at rest.

As the molecules act upon each ctber with several unecual attractive and repulsive forces, some of their inclinations, when ever they are in motion, are always gratified, while others are offencled. But these different sensations are necessarily unequal with regard to condition and intensity, according as they are caused by the general attraction of gravitation, by the general repulsion of heat and of elasticity, by electric and magnetic attraction and repulsion, or by chemical affinity. The simplest organisms which we know, if I may use this expression, the molecules of chemical elements, are therefore simultaneously influenced by several qualitatively and quantitatively different sensations, which conglomerate to a total sensation of pleasure or pain.

At the lowest and simplest stage of material organisation which we know, we therefore find on the whole the same phenomenon as we do at the highest stage, where it appears as conscious sensation. The difference is only one of gradation; at the highest stage the influences have only become so much more vivid in consequence of a vast accumulation of different material particles, and much more compound and intricate on account of the complicated organisation.

If we look upon mental life in its most general signification as the immaterial expression of the material phenomena, as the mediation between cause and effect, then we find it everywhere 
in nature. Mental force is the capacity of material particles to act upon each other. The mental phenomenon is the performance of this action, which consists in motion, therefore in a change of position, of the material particles and the forces inherent in them, and by this leads directly to a new mental occurrence. Thus the same mental chain encircles all material phenomena.

The human mind is nothing else but the highest development upon our earth of the mental phenomena which move and animate nature everywhere. But it is not the product of secretion of the cerebral substance; as such it would be withont further influence upon the brain, just as the secreted gall is of no further signification for the liver. On the contrary, sensation and consciousness have their firm seat in the brain, with which they are indissolubly united, and in which, by their intervention, new conceptions are formel and converted into actions. Just as the stone would not fall down if it did not feel the presence of the earth, so the trampled worm would not wriggle if it had no sensation, and the brain would not act reasonably if it had no consciousness.

This conception satisfies our causal demands entirely. For the naturalist it is a logical necessity to admit only differences of degree in finite nature. In the same way as there is a common measure for everything in space as well as for everything in time, so there must be a common measure for all mental phenomena. In the same way as there are gradations in material nature from the most simple to the most complex, so there must be similar gradations in mental nature, which is parallel to the former. It is true that in atoms and molecules we do not yet find pleasure and pain or love and hate pronounced with decision, but yet we find the first germs, as it were the original beginnings, of these feelings, and it would be the task of a comparative psychology to follow consciousness through unconscious sensation down to the insensible action of material particles.

But the domain of the mind offers far greater difficuities to our investigation than the matcrial domair, because we can only use our subjective perceptions as immediate experience, and because we do not possess a special organ of sense which enables us to make objective observations of other bodies. The obser. vation with our senses, which are organised for quite different objects, acquaints us only in a roundabout way and in a very defective manner with the mental occurrences in other beings, and our judgment of them is all the more uncertain the further we depart in nature from the human species itself. It will therefore, perhaps, never be possible to find the measure for the mental phenomena really, to determine it, and to raise compara: tive psychology to the rank of a natural science.

Natural knowledge remains limited to what is finite, the naturalist must therefore confine himself strictly to the finite only. The demand, which is often addressed to him, that he should have a more philosophical mind, that he should criticise in a philosophical manner, because it is impossible to avoid metaphysical speculation entirely, only shows how difficult it is to separate two absolutely different domains, which have once been mixed up only to produce general confusion. The power of education and habit also was, up to the most recent period, an obstacle in the way of a complete and radical separation of these two domains, and yet it is certain, and we know by experience, that every metaphysical addition turns natural science and natural inve stigation into a turbid and muddy alloy.

Natural science must be exact ; it must rigialy avoid evergthing which oversteps the limit of the finite and the intelligible, and which is transcendental; it must proceed in a strictly materialistic manner, because its sole object is finite, forceendowed matter; and it must not forget that this true materialism is an empirical and not a philosophical one, and that it is bounded by the same limits as those of the domain upon which it moves.

I do not wish to say by this that the naturalist is not allowed to philosophise, that he is forbidden to move in ideal and transcendental domains. But he ceases to be a naturalist, and the only thing, which from his vocation is perhaps of advantage to him, is that he keeps both domains strictly apart; that he knows how to treat the one as the pure domain of investigation and knowledge, and the other, while he frees it from everything that is finite, as the hidden domain of presentiment.

To the human mind, to our desire of investigation and knowledge, the whole sensually-perceptible world is open. We penetrate into the greatest distances by means of the telescope and calculation, and into the smallest spaces by means of the microscope and combination. We investigate the most complex and complicated organism, which belongs to ourselves, in the most varied directions. We recognise the forces and laws governing nature, and through this we subject the whole inorganic and organic world, as far as we can reach it. If man reviews the triumphs in the domains of science and power which have been obtained up to the present, and thinks of the still greater future conquests, then he may with pride feel himself lord of the world.

But what is this world, over which the human mind reigns? Not even a grain of sand in the eternity of space, not even a second in the eternity of time, and only an outwork of the true essence of the universe. Because even of the infinitesimal world, which is accessible to us, we only know what is changeable and perishable. All that is eternal and stable, the how and the wory of the universe, remains for ever incomprehensible to the human mind, and if it tries to overstep the limit of finiteness it can only puff itself up to a ridiculously-adorned idol, or desecrate the eternal and the divine by human disfiguration. Even the matured mind, which would have arrived at complete natural scientific insight, and would wish to free the divine of everything finite and perishable, could, in its restriction, make of divinity only a constitutional phantom-king, who, according to the words of a statesman recently deceased, would "reign, but not govern." In the finite world the eternal natural forces rule unalterably, and we recognise their effects in the laws of motion and change. Whether and how they are the tenor and expression of a conscious eternal design is past our comprehension.

If my predecessor, Prof. Du Bois Reymond, ended his address with the crushing words, Ignoramus, et ignorabimus, then I close mine with the conditional but more consolatory utterance that we do not merely know, but really understand the fruits of our investigations, and that our knowledge bears in itself the germ of an almost infinite growth, without, however, approaching omniscience by the smaliest step. If we practise reasonable resignation, if, as finite and perishable human beings, as we are, we are satisfied with human insight, instead of claiming divine knowledge, then we may say with full confidence-

$$
\text { "We know, and we shall know!" }
$$

\section{ON THE SOLAR ECLIPSE OF AGATHOCLES}

$$
\text { B.C. } 3 \text { IO (15th August). }{ }^{1}
$$

THE mean motion of the moon round the earth was formerly assumed to be constant, until Halley showed that it has been gradually increasing by a small amount during the last few thousand years. Halley made this discovery by the study of ancient solar eclipses, which were found always to occur to the eastward of their calculated places :-this indicates a slower mean motion of the moon in former times, as may be thus shown-a spectator in the northern hemisphere looking at a solar eclipse will face the south, having the west on his right hand, and the east on his left hand; and he will see the moon cross the sun's disc from right to left. When we calculate backwards to an old eclipse (attributing to the moon her present mean motion), we are, in fact, unwinding, from left to right, the path she has described since the eclipse happened, and by this unwinding process we find that we always place the moon to the right (zvest) of the place where she was actually when the eclipse occurred. Thus, all the ancient eclipses being observed at places to the eastward (left) of their calculated places of observation, we learn that the moon's mean motion was formerly slower than it now is The coefficient of the moon's mean motion, found by Halley, from ancient eclipses, was

$$
10.2 \times n^{2},
$$

where $n$ is the number of centuries.

The acceleration of the moon's mean motion was first explained by Laplace, who showed that the mean central disturbing force of the sun, by which the moon's gravity towards the earth is diminished, depends not only on the sun's mean distance, but on the eccentricity of the earth's orbit. This eccentricity has been diminishing for many ages, while the mean distance remains unaltered. In consequence of this, the sun's mean disturbing force is diminishing, and, consequently, the attraction of the moon towards the earth has been increasing, and with it, of course, the mean motion of the moon has been also increasing. The calculations of Laplace, confirmed and extended by Damoiseau

I Paper read before the Mathematical Section of the British Association, Plymouth, I877, by Rev. Dr. Samuel Haughton, F.R.S. (Trin. Coll. Dublin.) 